\title{
FORMAS DE PRESCRIPCIÓN EN LA ORTOGRAFÍA DE LA RAE DE LA PRESCRIPCIÓN A LA DESCRIPCIÓN: LA NUEVA TENDENCIA
}

\author{
JuAN CRESPo \\ Universidad de Málaga \\ zzcrespo@uma.es
}

\begin{abstract}
Resumen
Comparative study of the norms about the use of capital letters in the Ortografia of the Spanish Royal Academy 1974 and 1999: inventory and statistics. Evolution of patterns of prescription and description. Trends in norms.
\end{abstract}

\section{Introducción}

El folleto de la Ortografía de la Real Academia Española de 1974 ha estado vigente un cuarto de siglo'. Este opúsculo cumplía el mandato del IV Congreso de Academias de la Lengua Española, celebrado en Buenos Aires en 1964. El encargo consistía en

$[1]^{2}$ preparar un folleto que fundiese su Ortografia tradicional con las Nuevas Normas de Prosodia y Ortografía declaradas de aplicación preceptiva desde $1 .^{\circ}$ de enero de 1959. Por el momento, la Real Academia se había limitado a publicar las Normas reformadas, como apéndice a su Gramática. La publicación como apéndice [2] respondía a la urgencia de darlas a conocer cuanto antes; pero obligaba al lector a un cotejo incómodo de la Ortografia anterior con los preceptos nuevos. Por otra parte, [3] al interpretar algunas normas yuxtapuestas, que a veces se excluyen, podían producirse dudas en el ánimo de los maestros y entre los autores de libros escolares encargados de difundir la Ortografia oficial. Con la preparación e impresión del presente opúsculo cumple la Real Academia Española el honroso mandato [...], a fin de [4] asegurar y divulgar la unidad ortográfica, que es la base necesaria de la unidad de la lengua escrita en todos los países hispánicos ${ }^{3}$.

De la lectura del texto académico, se pueden colegir sus objetivos, ordenados según la numeración entre corchetes que he establecido. Esos objetivos revelan deficiencias de siste-

\footnotetext{
1 Real Academia Española, Ortografia ("Publicación que incorpora al texto tradicional las Nuevas Normas declaradas de aplicación preceptiva desde $1^{\circ}$ de enero de 1959. Segunda edición corregida y aumentada"). Imprenta Aguirre, Madrid, 1974, 47 págs. La primera edición es de 1969. Citada como OraE/74.

2 Intercalo entre corchetes la numeración de los objetivos de la Ortografia de 1974.

3 Real Academia Española, Ortografia de 1974, citada, pág. 3.
} 
$\mathrm{ma}^{4}$ en los referidos textos académicos sobre la materia: publicación y difusión inadecuadas ([edición del] 74-1), con urgencia (74-2) y de forma yuxtapuesta, a veces, excluyente (74-3) que hasta planteaba dudas en maestros y redactores de libros. La solución: un texto único, el folleto de 1969 (1. ${ }^{\mathrm{a}}$ ed.) y 1974 (2. ${ }^{\mathrm{a}}$ ed.) de la Ortografía para conseguir la unidad de la lengua española escrita (74-4).

Transcurridos, hasta 1999, entre cuarenta y veinticinco años -según la fecha que se tome como referencia: 1959, 1969 o $19744^{5}$ las Academias reconocen que los hispanohablantes solicitaban aclaraciones de normas ortográficas vigentes (ORAE de 1969-1974) porque seguían con dudas ortográficas y, para despejarlas, proponían una nueva ortografía accesible, clara y sistemática (99-1). Las Academias, atentas a estas peticiones y sabedoras de que las dudas en materia ortográfica son enemigas de la necesaria unidad de la lengua escrita, han corregido, actualizado, acrecentado y precisando la edición de 1974 (99-2):

[1] Han sido muchos los hispanohablantes que en los últimos tiempos se han dirigido a la Real Academia Española solicitando aclaraciones de normas ortográficas, planteando dudas y sugiriendo, en fin, la conveniencia de presentar la Ortografia de un modo más sistemático, claro y accesible. [2] A eso responde esta nueva edición que la Academia ha preparado en estrecha colaboración con las corporaciones hermanas de América y de Filipinas, corrigiendo, actualizando y acrecentando la versión anterior con precisiones y ejemplos. [3] Los detallados informes de las distintas Academias han permitido lograr una Ortografia verdaderamente panhispánica. [4] Apenas hay en ella novedad de doctrina, pero se recoge, ordena y clarifica toda la que tenía dispersa la Academia en Ios últimos tiempos y se refuerza la atención a las variantes de uso americanas [pág. xIII]. $\|[5]$ Presentamos, pues, esta nueva versión de la Ortografia académica, que se ha procurado [6] modernizar en el estilo, [7] actualizar en los ejemplos, [8] aliviar de tecnicismos, [9] ilustrar con referencias históricas y [10] desmenuzar la casuística, [11] pensando siempre en el gran público al que va dirigida. [12] Se diferencian convenientemente, por medios tipográficos, lo que son normas de lo que no es otra cosa que [13] orientación práctica para el uso, e igualmente [14] otros aspectos del contenido. [15] Todo ello fundado, es importante advertirlo, en la última edición del Diccionario académico, de 1992, y en las adiciones y enmiendas a este repertorio que la Corporación ha aprobado con posterioridad [págs. XVII-XIX]"6.

Los años transcurridos entre una y otra edición no parecen tantos en la vida de una lengua escrita como para que se justifiquen todas esas labores; antes bien, hay que atribuirlas a que el texto académico mismo no estaba enfocado a sus usuarios. La Institución reconoce

\footnotetext{
4 Ángel Rosenblat, en Actuales normas ortográficas y prosódicas de la Academia Española, Oficina de Educación Iberoamericana (Madrid), Ediciones de Promoción Cultural, Barcelona, 1974, estudia y compara magistralmente la Ortografia incluida como "Parte cuarta" de la Gramática de la Academia (edición de 1931, por ejemplo), la Ortografia de 1969, la "Ortografia" incluida estructuralmente en el capítulo "Fonología" del Esbozo de una nueva gramática de la lengua española y la "ortografía practicada" en el Diccionario académico. José Polo preparó un volumen del maestro de gramáticos Salvador Fernández Ramírez, La meva gramática académica. El camino hacia el Esbozo (1973), Editorial Paraninfo, Madrid, 1987, en el que recoge, como complemento útil de dicho volumen, el trabajo “El Esbozo de la Academia (perspectiva bibliográfica)”, BRAE, LXV-234/1985, págs. 101-120, donde su autor, J. Polo, expone cómo refundir los textos dispersos de la Academia en materia de ortografia.

5 Véase nota 1.

6 Real Academia Española, Ortografía de la lengua española. "Edición revisada por las Academias de la Lengua Española", Espasa, Madrid, 99. Las páginas citadas corresponden al prólogo. Citada como ORAE/99.
} 
que esta edición de 1999 es verdaderamente panhispánica ${ }^{7}$ (99-3). En contradicción parcial con lo que expone en el argumento (99-2), en el (99-4), manifiesta que "apenas hay en ella novedad de doctrina", sino que "recoge, ordena y clarifica toda la que tenía dispersa" (99-5); por lo tanto, o bien, ORAE/74 no cumplió acertadamente con el mandato de fundir la ortografía antigua con las nuevas normas (74-1) para solucionar el cotejo incómodo de los textos académicos dispersos, lo que producía dudas (74-2 y 3), y, ya sin ellas, conseguir la unidad ortográfica (74-4); o bien, entre ediciones, la Corporación volvió a dispersar tal cantidad de doctrina que, de nuevo, en ese corto tiempo, necesitó recogerla, ordenarla y clasificarla (99-5). He aquí, pues, otro enemigo de la unidad del idioma: la dispersión académica de doctrina que, a su vez, produce dudas, otro enemigo que procedia de los argumentos [2 y 3 ] de la edición de 1974, que consideré antes.

La nueva versión de la Ortografia de 1999, además de por los argumentos [1, 2 y 3] de la edición de 1999, es nueva -dice la Corporación- porque moderniza el estilo, actualiza ejemplos, alivia los tecnicismos, ilustra y desmenuza la casuística, pensando en el gran público (99-11). Comprobemos cómo han procedido las Academias en tal modernización, por ejemplo, en materia de mayúsculas y minúsculas ${ }^{8}$. Para efectuar tal comprobación y para que el lector interesado pueda tener la visión completa unitaria de las ediciones de la Ortografia de 1974 y 1999, las reproduzco íntegramente. El estudio comparado lo establezco por medio de la composición confrontada de ambas ediciones en formato de tablas, columnas, filas y celdas. En la columna de la izquierda, ORAE/99, la vigente; en la columna derecha, la ORAE/74. He extraído de los textos académicos, una vez "desmenuzados" (99-10), las normas que contienen; las he insertado en filas y celdas, rigiendo, a causa de su vigencia, el orden de ORAE/99 y, en función de este, altero el orden de ORAE/749. Las celdas vacías en la columna derecha indican gráficamente que las normas de ORAE/99 en la columna de la izquierda no están en ORAE/74 y, por lo tanto, son normas nuevas; las celdas vacias en la columna de la izquierda indican que las normas contenidas en las celdas a la derecha de la misma fila no están en ORAE/99. Con el subrayado sencillo marco las fórmulas empleadas por las Academias en las normas para la prescripción y la descripción de usos; con el subrayado doble, indico el estilo de ORAE/74 "modemizado" en ORAE/99 (99-6). El borde discontinuo entre celdas señala que he convertido un punto y aparte en punto y seguido para "desmenuzar" la casuística de algunos apartados con prescripción y orientación de uso múltiples. Las notas a pie de página del ORAE/99 las agrupo con el texto de la llamada de nota y conservo el filete de nota para indicarlo. Las letras negritas y cursivas son de los originales:

7 Las Academias han tardado 48 años en ponerse de acuerdo, desde 1951 (fecha del Primer Congreso de Academias en Méjico; el segundo en Madrid, 1956; Bogotá, 1960, Buenos Aires, 1964, Quito, 1968, Caracas, 1972; Madrid, 1994...) hasta 1999.

8 Este trabajo incluía, en su modalidad oral, el análisis de la acentuación y puntuación (Primer Foro Hispánico de Ortotipografia y Entorno de la Escritura, Málaga, 13-16 de diciembre de 1999. Mesa redonda con José Martínez de Sousa y José Polo).

9 Empleo el envío véase en celda superior para ahorrar espacio cuando el contenido correspondiente a esa celda se encuentra inserto en celda próxima. 


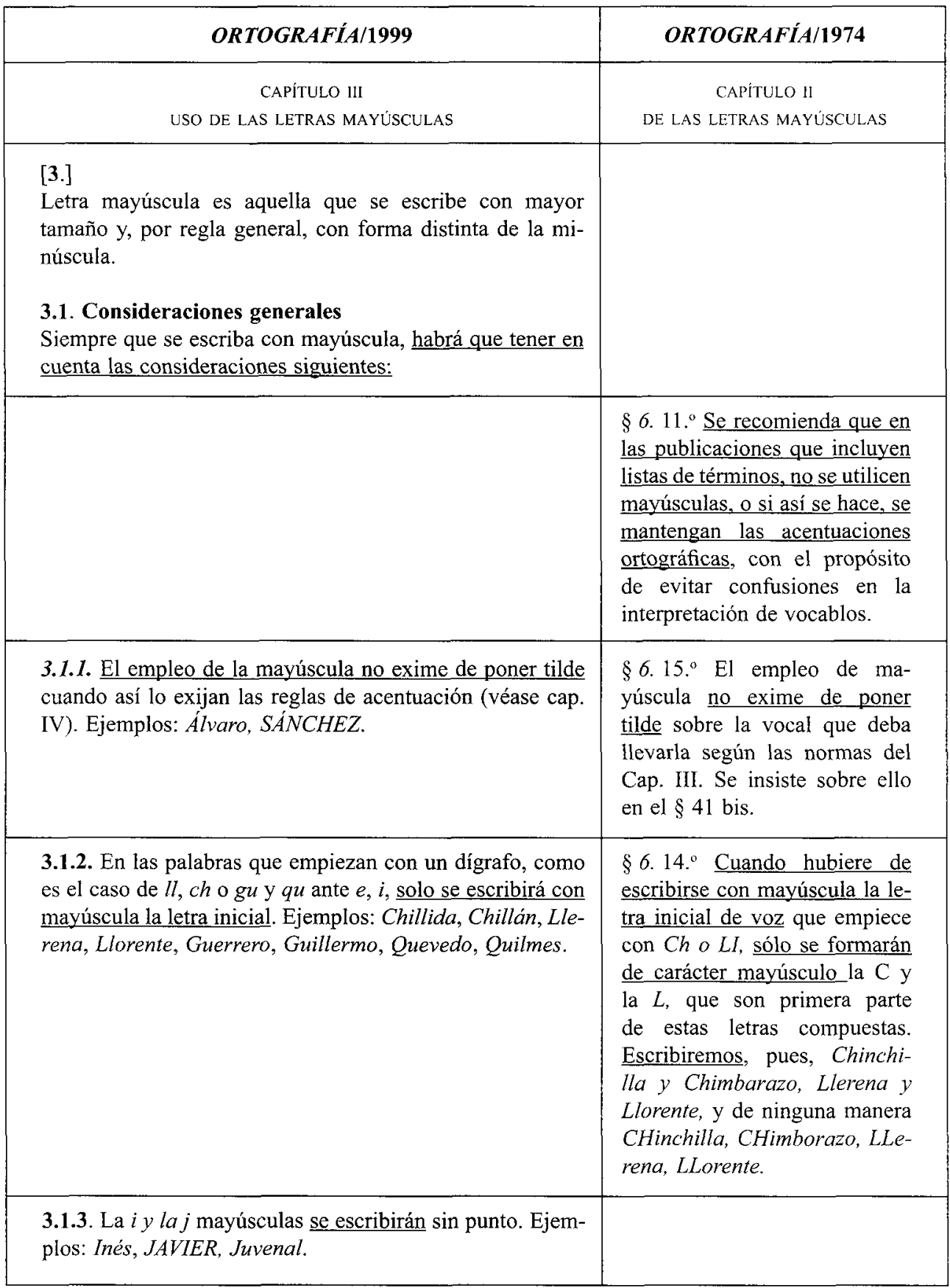




\begin{tabular}{|l|}
\hline ORTOGRAFÍA/1999 \\
\hline 3.2. Mayúsculas en palabras o frases enteras \\
En ocasiones se emplean letras mayúsculas para destacar \\
palabras o frases enteras de un escrito. Suele hacerse así:
\end{tabular}

3.2.1. En las cubiertas y portadas de los libros impresos, en los títulos de cada una de sus divisiones internas (partes, capítulos, escenas, etc.) y en las inscripciones monumentales. Por ejemplo:

\section{BENITO PÉREZ GALDÓS \\ FORTUNATA Y JACINTA}

\section{ORTOGRAFÍA/1974}

$\$ 5$ En lo manuscrito no suelen escribirse con letras mayúsculas palabras o frases enteras.

$\S 5$. a) En las portadas de los libros impresos, en los títulos de sus divisiones y en las inscripciones monumentales, lo más común es usar de solas mayúsculas, todas, generalmente, de igual tamaño. Los nombres propios, títulos de obras, dicciones y aun cláusulas que se quiera hacer resaltar, pueden escribirse con todas sus letras mayúsculas; pero en cualquiera voz en que se haya de emplear letra mayúscula con una o con diferentes minúsculas, aquélla ha de ser la inicial o primera de la dicción.

3.2.2. En las siglas y acrónimos. Ejemplos: ISBN, UNESCO, OTI, OMS ${ }^{25}$.

25 Se escribirán con minúscula, en cambio, los que con el uso se han convertido en nombres comunes. Por ejemplo: inri, láser, radar. Así los recoge el Diccionario de la Academia.

3.2.3. En las cabeceras de diarios y revistas. Ejemplos: $H E-$ RALDO DE ARAGÓN, EL TIEMPO, LA VANGUARDIA, LA NACIÓN.

3.2.4. En la numeración romana ${ }^{26}$. Se utiliza esta para significar el número ordinal con que se distinguen personas del mismo nombre (especialmente papas y reyes), como Pio $V$, Felipe II, Fernando III; el número de cada siglo, como siglo $x v i$; el de un tomo, libro, parte, canto, capítulo, título, ley, clase y otras divisiones, y el de las páginas que así vayan numeradas en los prólogos y principios de un volumen ${ }^{27}$.

26 En ningún caso se utilizarán letras voladas tras los números romanos. No se escribirá, pues, ${ }^{*}$ III. ${ }^{a}$ parte.

${ }_{27}$ Algunos impresores utilizan letras minúsculas en este ủltimo caso: página xxii, xvi, etc.
$\S 6.13^{\circ}$ La numeración romana se escribe hoy con letras mayúsculas, y se emplea para significar el número con que se distinguen personas del mismo nombre, como Pio V, Fernando III, el número de cada siglo, como el actual, el XX de la Era cristiana; el de un tomo, libro, parte, canto, capítulo, título, ley, clase y otras divisiones, y el de las páginas en los prólogos $\mathrm{y}$ principios de un volumen. 


\begin{tabular}{|l|}
\hline ORTOGRAFí $/ 1999$ \\
\hline 3.2.5. En textos jurídicos y administrativos -decretos, sen- \\
tencias, bandos, edictos, certificados o instancias-, el verbo \\
o verbos que presentan el objetivo fundamental del docu- \\
mento. Ejemplos: CERTIFICA, EXPONE, SOLICITA.
\end{tabular}

\subsection{Mayúsculas inniciales}

El uso de la mayúscula inicial se rige por la posición que ocupa la palabra ( $y$, en consecuencia, por la puntuación exigida en cada caso), por su condición o categoría de nombre propio y por otras circunstancias.

\subsubsection{En función de la puntuación}

Se escribirán con letra inicial mayúscula:

a) La primera palabra de un escrito y la que vaya después de punto. Por ejemplo:

Hoy no iré. Mañana puede que si.

b) La palabra que sigue a los puntos suspensivos, cuando estos cierran un enunciado (véase 5.5). Por ejemplo:

No sé si... Si, iré.

c) La que sigue a un signo de cierre de interrogación (?) o de exclamación (!), si no se interpone coma, punto y coma o dos puntos (véase 5.6.4). Por ejemplo:

¿Dónde? En la estantería.

d) La que va después de dos puntos, siempre que siga a la fórmula de encabezamiento de una carta o documento jurídicoadministrativo (Muy señor mío: Le agradeceré...), o reproduzca palabras textuales (Pedro dijo: "No volveré hasta las nueve"). Véanse 5.3.2, 5.3.3 y 5.3.6.

\subsubsection{En función de la condición o categoría}

Se escribirá con letra inicial mayúscula todo nombre propio, como son los siguientes:
§ 6. 1." La primera palabra de un escrito y la que vaya después de punto.
ORTOGRAFIA/1974

$\S 6$. Se escribirán con letra inicial mayúscula:

§ 6. 1." La primera palabra de un escrito y la que vaya después de punto.
\& 6. 2." Todo nombre propio; v. gr.: Dios, Jehovah, Jesús, Luzbel, Platón, Pedro, María, Alvarez, Pantoja, Apolo, Caliope, Amadis de Gaula; Europa, España, Castilla, Toledo, Madrid, Carabanchel, La Zarzuela; Cáucaso, Himalaya, Adriático, Tajo, Aganipe; Bucéfalo, Babieca, Rocinante. 


\begin{tabular}{|c|c|}
\hline ORTOGRAFIA/1999 & ORTOGRAFIA $/ 1974$ \\
\hline $\begin{array}{l}\text { a) Nombres de persona, animal o cosa singularizada. } \\
\text { Ejemplos: Pedro, Alberto, Beatriz, Maria, Platón, Cau- } \\
\text { policán, Rocinante, Platero, Colada, Olifante. }\end{array}$ & $\begin{array}{l}\text { §. 2. Todo nombre propio; } \\
\text { v. gr.: Dios, Jehovah, Jesús, } \\
\text { Luzbel, Platón, Pedro, Maria } \\
\text { [...] Aganipe; Bucéfalo, Babie- } \\
\text { ca, Rocinante [...]. }\end{array}$ \\
\hline $\begin{array}{l}\text { b) Nombres geográficos. Ejemplos: América, España, } \\
\text { Jaén, Honduras, Salta, Cáucaso, Himalaya, Adriático, } \\
\text { Tajo, Pilcomayo. }\end{array}$ & $\begin{array}{l}\text { \$6.2. Todo nombre propio; } \\
\text { v. gr.: [...] Europa, España, } \\
\text { Castilla, Toledo, Madrid, } \\
\text { Carabanchel, La Zarzuela; } \\
\text { Cáucaso, Himalaya, Adriático, } \\
\text { Tajo [...]. }\end{array}$ \\
\hline $\begin{array}{l}\text { Cuando el artículo forme parte oficialmente del nom- } \\
\text { bre propio, ambas palabras comenzarán por mayúscula. } \\
\text { Ejemplos: El Salvador La Zarzuela, La Habana, Las } \\
\text { Palmas }\end{array}$ & $\S 6.2^{\circ}[\ldots]$ La Zarzuela. \\
\hline $\begin{array}{l}\text { Se escribe con mayúscula el nombre que acompaña a } \\
\text { los nombres propios de lugar, cuando forma parte del } \\
\text { topónimo. Ejemplos: Ciudad de México, Sierra Neva- } \\
\text { da, Puerto de la Cruz. Se utilizará la minúscula en los } \\
\text { demás casos. Ejemplos: la ciudad de Santa Fe, la sierra } \\
\text { de Madrid, el puerto de Cartagena. }\end{array}$ & \\
\hline c) Apellidos. Ejemplos: Alvarez, Pantoja, Martínez. & 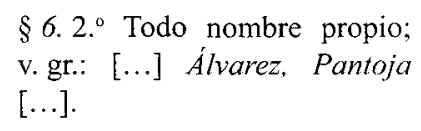 \\
\hline $\begin{array}{l}\text { En el caso de que un apellido comience por preposi- } \\
\text { ción, por artículo o por ambos, estos se escribirán con } \\
\text { mayúscula solo cuando encabecen la denominación. Por } \\
\text { ejemplo: señor De Felipe frente a Diego de Felipe. }\end{array}$ & \\
\hline $\begin{array}{l}\text { Se escribirán también con mayúscula los nombres de } \\
\text { las dinastías derivados de un apellido. Ejemplos: Bor- } \\
\text { bones, Austrias, Capetos. }\end{array}$ & \\
\hline $\begin{array}{l}\text { d) Nombres de constelaciones, estrellas, planetas o as- } \\
\text { tros, estrictamente considerados como tales. Ejemplos: } \\
\text { La Osa Mayor está formada por siete estrellas. } \\
\text { El Sol es el astro central de nuestro sistema pla- } \\
\text { netario. } \\
\text { En el illtimo eclipse, la Tierra oscureció totalmente } \\
\text { a la Luna. }\end{array}$ & \\
\hline
\end{tabular}




\begin{tabular}{|c|c|}
\hline ORTOGRAFIÁ/1999 & ORTOGRAFIA/1974 \\
\hline $\begin{array}{l}\text { Por el contrario, si el nombre se refiere, en el caso del Sol } \\
\text { y de la Luna, a los fenómenos sensibles de ellos derivados, } \\
\text { se escribirá con minúscula: } \\
\text { Tomar el sol. } \\
\quad \text { Noches de luna llena. }\end{array}$ & \\
\hline $\begin{array}{l}\text { En el caso de la Tierra, todos los usos no referidos a ella } \\
\text { en cuanto planeta aludido en su totalidad se escribirán } \\
\text { también con minúscula: } \\
\text { El avión tomó tierra. } \\
\quad \text { Esta tierra es muy fértil. } \\
\quad \text { La tierra de mis padres. }\end{array}$ & \\
\hline $\begin{array}{l}\text { e) Nombres de los signos del Zodiaco. Ejemplos: Tauro, } \\
\text { Aries, Libra. De igual modo, los nombres que aluden a la } \\
\text { característica principal de estos signos, como Balanza (por } \\
\text { Libra), Toro (por Tauro), Carnero (por Aries), Gemelos } \\
\text { (por Géminis), Cangrejo (por Cáncer), Pez (por Piscis), } \\
\text { Escorpión (por Escorpio), León (por Leo), Virgen (por } \\
\text { Virgo). }\end{array}$ & \\
\hline $\begin{array}{l}\text { Cuando el nombre propio deja de serlo porque designa a } \\
\text { las personas nacidas bajo ese signo, se escribirá con mi- } \\
\text { núscula. Por ejemplo: } \\
\quad \text { Juan es tauro. }\end{array}$ & \\
\hline $\begin{array}{l}\text { f) Nombres de los puntos cardinales, cuando nos referimos } \\
\text { a ellos explícitamente. Por ejemplo: } \\
\text { La brújula señala el Norte. }\end{array}$ & \\
\hline $\begin{array}{l}\text { Cuando el nombre se refiere a la orientación o dirección } \\
\text { correspondientes a estos puntos, se escribirá con minús- } \\
\text { cula. Ejemplos: } \\
\text { El norte de la ciudad. } \\
\text { Viajamos por el sur de España. } \\
\quad \text { El viento norte. }\end{array}$ & \\
\hline $\begin{array}{l}\text { g) Nombres de festividades religiosas o civiles. Ejemplos: } \\
\text { Pentecostés, Epifania, Navidad, Corpus, Día de la Consti- } \\
\text { tución, Dí de la Independencia. }\end{array}$ & \\
\hline $\begin{array}{l}\text { h) Nombres de divinidades. Ejemplos: Dios, Jehová, Alá, } \\
\text { Apolo, Juno, Amón. }\end{array}$ & $\begin{array}{l}\text { §. 2. } .^{\circ} \text { Todo nombre propio; } \\
\text { v. gr.: Dios, Jehovah, }[\ldots] \\
\text { Apolo }[\ldots] .\end{array}$ \\
\hline $\begin{array}{l}\text { i) Libros sagrados. Ejemplos: Biblia, Corán, Avesta, Tal- } \\
\text { mud. }\end{array}$ & \\
\hline
\end{tabular}




\begin{tabular}{|c|c|}
\hline ORTOGRAFÍL/1999 & ORTOGRAFÍIA/1974 \\
\hline $\begin{array}{l}\text { j) Atributos divinos o apelativos referidos a Dios, Jesu- } \\
\text { cristo o la Virgen María. Ejemplos: Todopoderoso, Cristo, } \\
\text { Mesias, Inmaculada, Purísima. }\end{array}$ & $\begin{array}{l}\S 6.3 .^{\circ} \text { Los atributos divinos, } \\
\text { como Criador y Redentor } \\
{[\ldots] .}\end{array}$ \\
\hline \multicolumn{2}{|l|}{$\begin{array}{l}\text { k) Nombres de las órdenes religiosas. Ejemplos: Cartuja, } \\
\text { Merced, Temple, Carmelo. }\end{array}$} \\
\hline \multicolumn{2}{|l|}{ 1) Marcas comerciales. Ejemplos: Coca-Cola, Seat. } \\
\hline \multicolumn{2}{|l|}{$\begin{array}{l}\text { En los casos anteriores, cuando el nombre propio se use } \\
\text { como común, es decir, cuando pase a designar un género } \\
\text { o una clase de objetos o personas, deberá escribirse con } \\
\text { minúscula. Ejemplos: un herodes, una venus. Lo mismo } \\
\text { sucede cuando se designa algo con el nombre del lugar del } \\
\text { que procede, o con el de su inventor, fabricante, marca o } \\
\text { persona que lo popularizó. Ejemplos: un jerez, un oporto, } \\
\text { una aspirina, un quinqué, unos quevedos. }\end{array}$} \\
\hline \multicolumn{2}{|l|}{$\begin{array}{l}\text { En este último caso, cuando se quiere mantener viva la } \\
\text { referencia al autor, creador o fabricante de la obra, se } \\
\text { utilizará la mayúscula inicial. Ejemplos: un Casares, dos } \\
\text { Picassos, un Seat. }\end{array}$} \\
\hline $\begin{array}{l}\text { 3.3.3. En función de otras circunstancias } \\
\text { Se escribirán con letra inicial mayúscula: }\end{array}$ & $\begin{array}{l}\text { §6.3. Los atributos divinos, } \\
\text { como Criador y Redentor; } \\
\text { los títulos y nombres de dig- } \\
\text { nidad, como Sumo Pontifice, } \\
\text { Duque de Osuna, Marqués de } \\
\text { Villena; los nombres y apodos } \\
\text { con que se designa a determi- } \\
\text { nadas personas, como el Gran } \\
\text { Capitán, Alfonso el Sabio, } \\
\text { García el Trémulo, y particu- } \\
\text { larmente los dictados generales } \\
\text { de jerarquía o cargo importante } \\
\text { cuando equivalgan a nombres } \\
\text { propios. Así, en las respectivas } \\
\text { historias de Paulo V, Felipe III } \\
\text { y D. Pedro Téllez Girón, v. gr.: } \\
\text { se escribirán con mayúscula el } \\
\text { Papa, el Rey y el Duque cuan- } \\
\text { tas veces fueren nombrados en } \\
\text { esta forma aquellos personajes; } \\
\text { pero se deberá usar de minús- } \\
\text { cula, por ejemplo, en la vulgar } \\
\text { sentencia: El papa, el rey y el } \\
\text { duque están sujetos a morir, } \\
\text { como lo está el pordiosero. }\end{array}$ \\
\hline
\end{tabular}




\section{ORTOGRAFÍA/1999}

\section{ORTOGRAFÍI/1974}

$\$ 6.3 .^{\circ}[\ldots]$ los nombres y apodos con que se designa a determinadas personas, como el Gran Capitán, Alfonso el Sabio, Garcia el Trémulo [...].

b) En general, cuando por antonomasia se emplean apelativos usados en lugar del nombre propio, como el Mantuano (por Virgilio), el Sabio (por Salomón), el Magnánimo (por el rey Alfonso $V$ o se designan conceptos o hechos religiosos (la Anunciación, la Revelación, la Reforma).

c) Las advocaciones de la Virgen. Ejemplos: Guadalupe, Rocío. Y las celebraciones a ellas dedicadas. Ejemplos: el Pilar, el Rocio.

d) Los tratamientos, especialmente si están en abreviatura. Ejemplos: $V S$. (Usía), U. o V (usted), etc.

Cuando se escribe con todas sus letras, usted no debe llevar mayúscula.

Fray Luis (referido, por ejemplo, a Fray Luis de León), Sor Juana (referido a Sor Juana Inés de la Cruz), San Antonio, etc., son acuñaciones que funcionan como nombres propios.

e) Los sustantivos y adjetivos que componen el nombre de instituciones, entidades, organismos, partidos políticos, etc. Ejemplos: la Biblioteca Nacional, la Inquisición, el Tribunal Supremo, el Museo de Bellas Artes, el Colegio Naval, la Real Academia de la Historia, el Instituto Caro y Cuervo, la Universidad Nacional Autónoma de México, el Partido Demócrata.

f) Los nombres, cuando significan entidad o colectividad como organismo determinado. Ejemplos: la Universidad, el Estado, el Reino, la Marina, la Justicia, el Gobierno, la Administración, la Judicatura. Ejemplos:

La Magistratura mostró su oposición al proyecto.

La Iglesia celebra mañana esa festividad.
$\$ 6.3 .^{\circ}$ [véase en celda superior].
§ 6. 4. ${ }^{\circ}$ Los tratamientos, y especialmente si están en abreviatura, como Sr: D. (Señor Don), U. o $V$. (usted), $V . S$. (Usia), etcétera.

$\S 6.4 .^{\circ}[\ldots]$ Usted, cuando se escribe con todas sus letras, no debe llevar mayúscula, a no ser en comienzo de párrafo o después de punto.

§6.6. Los substantivos y adjetivos que compongan el nombre de una institución, de un cuerpo o establecimiento: el Supremo Tribunal de Justicia; el Museo de Bellas Artes; el Colegio Naval; la Real Academia de la Historia.

$\S 6.5$. Ciertos nombres colectivos, en casos como éstos: el. Reino representó a $S$. $M$. contra tales desórdenes; el Clero lo habia hecho antes.

Pero se utilizará la minúscula inicial en casos como: Ejerció su magistratura con brillantez.

Visitó la iglesia del pueblo. 


\begin{tabular}{l} 
ORTOGRAFIA/1999 \\
\hline g) La primera palabra del título de cualquier obra. Ejem- \\
plos: El rayo que no cesa, Luces de bohemia, El mundo \\
es ancho y ajeno, Cantos de vida y esperanza, El perro \\
andaluz, Los girasoles.
\end{tabular}

En las publicaciones periódicas y colecciones, en cambio, se escriben con mayúscula los sustantivos y adjetivos que forman el título. Ejemplos: Nueva Revista de Filología Hispánica, El Urogallo, Biblioteca de Autores Españoles

\section{ORTOGRAFIA/1974}

$\S 6.7 .^{\circ}$ Es potestativo escribir con mayúscula o minúscula los sustantivos y adjetivos que entren en el título de cualquier obra: Historia de la Literatura Española, o Historia de la literatura española; La Vida es Sueño, o La vida es sueño; Código Civil, o Código civil. Claro es que los nombres propios deben escribirse con mayúscula: Historia del descubrimiento de América.

$\S 6.9 .^{\circ}$ No es preceptivo, pero responde a uso personal frecuente, iniciar con mayúscula palabras $[. .$.$] como denotación$ de disciplinas científicas, la Psicología, la Geografia, la Matemática, etc. [...].

Pero escribiremos con minúscula:

Me gustan las matemáticas de este curso.

Llaman filosofia de la vida a lo que es pura vulgaridad.

La psicologia de los niños es complicada.

i) El primero de los nombres que designan especies de animales y plantas. Ejemplos: Pimpinella anisum, Felis leo.

(Además, al imprimirlos, se hará en cursiva).

j) Los nombres, latinos o no, de los grupos taxonómicos zoológicos y botánicos superiores al género. Ejemplos: orden Roedores, familia Leguminosas.

Se escribirán con minúscula, en cambio, cuando sean adjetivos (por ejemplo: animal roedor) o sustantivos que no signifiquen orden (por ejemplo: una buena cosecha de leguminosas $)^{28}$. 


\begin{tabular}{|c|c|}
\hline ORTOGRAFÍL/1999 & ORTOGRAFÍA/1974 \\
\hline $\begin{array}{l}28 \text { Antiguamente. se escribía con mayúscula la primera } \\
\text { palabra de cada verso. Por esta costumbre, las letras ma- } \\
\text { yúsculas reciben también el nombre de versales }\end{array}$ & $\begin{array}{l}\S 6.12 .^{\circ} \text { Suele emplearse ma- } \\
\text { yúscula a principio de cada } \\
\text { verso, de donde las letras de } \\
\text { esta forma tomaron el nombre } \\
\text { de versales. En la poesía mo- } \\
\text { derna es frecuente encabezar } \\
\text { los versos con minúscula, sal- } \\
\text { vo los que inician poema o van } \\
\text { después de punto. }\end{array}$ \\
\hline $\begin{array}{l}\text { 3.3.4. Suelen escribirse con mayúscula los nombres de de- } \\
\text { terminadas entidades cuando se consideran conceptos ab- } \\
\text { solutos. Ejemplos: la Libertad, la Ley, la Paz, la Justicia. }\end{array}$ & $\begin{array}{l}\S 6.9 .^{\circ} \text { No es preceptivo, pero } \\
\text { responde a uso personal fre- } \\
\text { cuente, iniciar con mayúscula } \\
\text { palabras representativas de } \\
\text { seres o conceptos que quien } \\
\text { escribe desea destacar por ve- } \\
\text { neración, respeto o énfasis: así, } \\
\text { entre católicos, los pronombres } \\
\text { Tú, Ti, Vos, Ell, Ella, referidos a } \\
\text { Dios o a la Virgen María; entre } \\
\text { juristas, el Derecho, la Ley; } \\
\text { como denotación de discipi- } \\
\text { nas científicas, la Psicologia, } \\
\text { la Geografia, la Matemática, } \\
\text { etc.; al designar fechas inicia- } \\
\text { les de cómputos cronológicos } \\
\text { como la Era cristiana, la } \\
\text { Hégira; en nombres de épocas } \\
\text { históricas, movimientos reli- } \\
\text { giosos, políticos o culturales, } \\
\text { etc., v. gr. la Antigüedad, la } \\
\text { Edad Media, el Siglo de Oro, } \\
\text { la Escolástica, la Reforma, } \\
\text { el Renacimiento, el Roman- } \\
\text { ticismo. En muchos de estos } \\
\text { casos la mayúscula orienta al } \\
\text { lector respecto al significado } \\
\text { que ha de dar a la palabra, con } \\
\text { exclusión de otras acepciones } \\
\text { posibles. }\end{array}$ \\
\hline
\end{tabular}




\begin{tabular}{|c|c|}
\hline ORTOGRAFÍA/1999 & ORTOGRAFIA/1974 \\
\hline \multicolumn{2}{|l|}{$\begin{array}{l}\text { Pero: } \\
\text { La libertad de expresión. } \\
\text { La ley de la gravedad. }\end{array}$} \\
\hline & $\begin{array}{l}\S 6.90^{\circ} \text { No es preceptivo, pero } \\
\text { responde a uso personal fre- } \\
\text { cuente, iniciar con mayúscula } \\
\text { palabras representativas de } \\
\text { seres o conceptos que quien } \\
\text { escribe desea destacar [...]. } \\
\text { En muchos de estos casos la } \\
\text { mayúscula orienta al lector } \\
\text { respecto al significado que } \\
\text { ha de dar a la palabra, con } \\
\text { exclusión de otras acepciones } \\
\text { posibles. }\end{array}$ \\
\hline $\begin{array}{l}\text { También se escriben con mavúscula inicial: } \\
\text { a) Los nombres de fechas o cómputos cronológicos, épo- } \\
\text { cas, acontecimientos históricos, movimientos religiosos, } \\
\text { políticos o culturales. Ejemplos: la Antigüedad, la Hégira, } \\
\text { la Escolástica, el Renacimiento }\end{array}$ & $\begin{array}{l}\S 6.9^{\circ} \text { [véase en celda supe- } \\
\text { rior]. }\end{array}$ \\
\hline $\begin{array}{l}\text { b) Los pronombres } T u, T i, \text { Tuyo, Vos, Él, Ella, en las alu- } \\
\text { siones a la Divinidad o a la Virgen María. }\end{array}$ & $\begin{array}{l}\S 6.9 .^{\circ} \text { [véase en celda supe- } \\
\text { rior]. }\end{array}$ \\
\hline $\begin{array}{l}\text { c) Conceptos religiosos como el Paraíso, el Infierno, etc., } \\
\text { siempre que se designen directamente tales conceptos, y } \\
\text { no en casos como Su casa era un paraíso o El infierno en } \\
\text { que vivía }\end{array}$ & \\
\hline $\begin{array}{l}\text { 3.4. Minúscula inicial } \\
\text { Se recomienda, en cambio, escribir con minúscula inicial } \\
\text { los nombres de los días de la semana, de los meses y de las } \\
\text { estaciones del año. Ejemplos: } \\
\quad \text { El lunes es su día de descanso. } \\
\text { La primavera empieza el } 21 \text { de marzo. }\end{array}$ & $\begin{array}{l}\S 6.10{ }^{\circ} \text { Cuando no encabecen } \\
\text { párrafo o escrito, o no formen } \\
\text { parte de un título, se reco- } \\
\text { mienda escribir con minúscula } \\
\text { inicial los nombres de los dias } \\
\text { de la semana, de los meses, de } \\
\text { las estaciones del año y de las } \\
\text { notas musicales. }\end{array}$ \\
\hline $\begin{array}{l}\text { 3.5. Empleos expresivos } \\
\text { En ocasiones, el uso de la mayúscula se debe a propósitos } \\
\text { expresivos, como sucede en los casos siguientes: } \\
\text { a) En los títulos, cargos y nombres de dignidad, como Rey, } \\
\text { Papa, Duque, Presidente, Ministro, etc. }\end{array}$ & $\begin{array}{l}\$ 6.3 .^{\circ}[\ldots] \text { los títulos y nombres } \\
\text { de dignidad, como Sumo Ponti- } \\
\text { fice, Duque de Osuna, Marqués } \\
\text { de Villena [...] y particular- } \\
\text { mente los dictados generales } \\
\text { de jerarquía o cargo importante } \\
\text { cuando equivalgan a nombres }\end{array}$ \\
\hline
\end{tabular}




\begin{tabular}{|c|c|}
\hline ORTOGRAFÍA/1999 & ORTOGRAFÍA/1974 \\
\hline & $\begin{array}{l}\text { propios. Así, en las respectivas } \\
\text { historias de Paulo V, Felipe III } \\
\text { y D. Pedro Téllez Girón, v. gr: } \\
\text { se escribirán con mayúscula el } \\
\text { Papa, el Rey y el Duque cuantas } \\
\text { veces fueren nombrados en esta } \\
\text { forma aquellos personajes; pero } \\
\text { se deberá usar de minúscula, por } \\
\text { ejemplo, en la vulgar sentencia: } \\
\text { El papa, el rey y el duque están } \\
\text { sujetos a morit, como lo está el } \\
\text { pordiosero. }\end{array}$ \\
\hline $\begin{array}{l}\text { Estas palabras se escribirán siempre con minúscula cuando } \\
\text { acompañen al nombre propio de la persona o del lugar al } \\
\text { que corresponden (ejemplos: el rey Felipe IV, el papa Juan } \\
\text { Pablo II, el presidente del Ecuador el ministro de Trabajo) } \\
\text { o estén usados [usadas] en sentido genérico (por ejemplo: } \\
\text { El papa, el rey y el duque están sujetos a morir, como lo } \\
\text { está cualquier otro hombre). }\end{array}$ & $\begin{array}{l}\$ 6.3 .^{\circ}[\ldots] \text { los títulos y nom- } \\
\text { bres de dignidad, [...] y particu- } \\
\text { larmente los dictados generales } \\
\text { de jerarquía o cargo importante } \\
\text { cuando equivalgan a nombres } \\
\text { propios. [...] pero se deberá } \\
\text { usar de minúscula, por ejem- } \\
\text { plo, en la vulgar sentencia: El } \\
\text { papa, el rey y el duque están } \\
\text { sujetos a morir, como lo está el } \\
\text { pordiosero. }\end{array}$ \\
\hline $\begin{array}{l}\text { Sin embargo, pueden escribirse con mayúscula cuando no } \\
\text { aparece expreso el nombre propio de la persona o del lugar } \\
\text { y, por el contexto, los consideramos referidos a alguien a } \\
\text { quien pretendemos destacar. Ejemplos: } \\
\text { El Rey inaugurará la nueva biblioteca. } \\
\text { El Papa visitará tres paises en su próximo viaje. }\end{array}$ & $\S 6.3 .^{\circ}$ [véase celda superior]. \\
\hline $\begin{array}{l}\text { También es costumbre particular de las leyes, decretos y } \\
\text { documentos oficiales escribir con mayúscula las palabras } \\
\text { de este tipo. Ejemplos: el Rey de España, el Presidente del } \\
\text { Gobierno, el Secretario de Estado de Comercio. }\end{array}$ & $\begin{array}{l}\S 6.8^{\circ} \text { En las leyes, decretos } \\
\text { y documentos oficiales suelen } \\
\text { escribirse con mayúscula to- } \\
\text { das las palabras que expresan } \\
\text { poder público, dignidad o } \\
\text { cargo importante, como Rey, } \\
\text { Principe, Republica, Regente, } \\
\text { Trono, Corona, Monarquia, } \\
\text { Estado, Gobierno, Ministro, } \\
\text { Senador, Diputado, Autoridad, } \\
\text { Justicia, Magistrado, Juez, } \\
\text { General, Jefe, Gobernador, } \\
\text { Alcalde, Director, Consiliario, } \\
\text { Secretario, etc. }\end{array}$ \\
\hline
\end{tabular}




\begin{tabular}{|l|l|}
\hline ORTOGRAFIA/1999 & ORTOGRAFİA/1974 \\
\hline b) En algunas palabras de escritos publicitarios, propagan- & \\
dísticos o de textos afines. Este uso, destinado a destacar & \\
arbitrariamente determinadas palabras, es idéntico al re- & \\
curso opuesto, consistente en emplear las minúsculas en & \\
lugares donde la norma exige el uso de mayúsculas. & \\
En ningún caso deben extenderse estos empleos de inten- & \\
ción expresiva de mayúsculas o minúsculas a otros tipos & \\
\hline de escritos. & \\
\hline
\end{tabular}

Las normas sobre mayúsculas y minúsculas en cifras

OrTOGRAFiA (mayúsculas y minúsculas)

1999-edición-1974

normas

TOTAL

67

36

mayúsculas todas las letras de una palabra o frase

uso potestativo mayúscula/minúscula

otras (acento, dígrafos, grafia de $i$ y $j$, letras voladas, cursiva, prácticas de impresores, etc.) NORMAS COMUNES A 1974 y 1999 


\section{Fórmulas comparadas de prescripción y descripción de uso}

\begin{tabular}{|c|c|}
\hline \multicolumn{2}{|c|}{$\begin{array}{l}\text { USO DE LAS LETRAS MAYÚSCULAS } \\
\text { Fórmulas de prescripción y descripción de uso }\end{array}$} \\
\hline Ortografia/99 & Ortografia/74 \\
\hline $\begin{array}{l}\text { Siempre que se escriba con mayúscula, } \\
\text { habrá que tener en cuenta las conside- } \\
\text { raciones siguientes ( } 3.1)\end{array}$ & \\
\hline $\begin{array}{l}\text { El empleo de la mayúscula no exime } \\
\text { de poner tilde ( } 3.1 .1)\end{array}$ & $\begin{array}{l}\text { Se recomienda }[\ldots] \text { no se utilicen mayúsculas, } \\
{[\ldots] \text { se mantengan las acentuaciones ortográficas }} \\
\left(\$ 6.11 .^{\circ}\right) \\
\text { No exime de poner tilde }\left(\$ 6.15^{\circ}\right)\end{array}$ \\
\hline $\begin{array}{l}\text { En ocasiones se emplean letras ma- } \\
\text { yúsculas }[\ldots] \text {. Suele hacerse así }(3.2) \text {, } \\
(3.2 .1-5)\end{array}$ & $\begin{array}{l}\text { No suelen escribirse con letras mayúsculas }(\$ 5) \\
\text { Lo más común es usar de solas mayúsculas }(\$ 5 . a) \\
\text { Se escribe hoy con letras mayúsculas }\left(\$ 6.13 .^{\circ}\right)\end{array}$ \\
\hline $\begin{array}{l}\text { Se escribirán con letra inicial mayúscu- } \\
\text { la }(3.3 .1 . a-d)\end{array}$ & $\begin{array}{l}\text { Se escribirán con letra inicial mayúscula }\left(\$ 6.6 .1 .^{\circ}-\right. \\
\left.6.14^{\circ}\right) \\
\text { Se escribirán con mayúscula }\left(\$ 6.3 .^{\circ}\right)\end{array}$ \\
\hline $\begin{array}{l}\text { Se escribirá con letra inicial mayúscula } \\
(3.3 .2 . a-l)\end{array}$ & \\
\hline $\begin{array}{l}\text { Cuando el artículo }[\ldots] \text { ambas palabras } \\
\text { comenzarán por mayúscula }(3.3 .2 . b)\end{array}$ & \\
\hline Se escribe con mayúscula $(3.3 .2 . b)$ & \\
\hline $\begin{array}{l}\text { Se escribirán con mayúscula solo cuan- } \\
\text { do }(3.3 .2 . c)\end{array}$ & \\
\hline $\begin{array}{l}\text { Se escribirán también con mayúscula } \\
(3.3 .2 . c)\end{array}$ & \\
\hline $\begin{array}{l}\text { Se utilizará la mayúscula inicial } \\
(3.3 .2 . l)\end{array}$ & \\
\hline $\begin{array}{l}\text { Se escribirán con letra inicial mayús- } \\
\text { cula (3.3.3) }\end{array}$ & \\
\hline $\begin{array}{l}\text { Se escriben con mayúscula los sustan- } \\
\text { tivos }(3.3 .3 . \mathrm{g})\end{array}$ & $\begin{array}{l}\text { Es potestativo escribir con mayúscula o minúscula } \\
\text { los sustantivos }\left(\$ 6.7 .^{\circ}\right) \\
\text { Claro es que los nombres propios deben escribirse } \\
\text { con mayúscula }\left(\$ 6.7 .^{\circ}\right)\end{array}$ \\
\hline
\end{tabular}


USO DE LAS LETRAS MAYÚSCULAS

Fórmulas de prescripción y descripción de uso

\begin{tabular}{|l|}
\hline \multicolumn{1}{|c|}{ Ortografia/99 } \\
\hline $\begin{array}{l}\text { Se escribirán con letra inicial mayús- } \\
\text { cula }(3.3 .3 . h)\end{array}$ \\
\hline $\begin{array}{l}\text { Se escribía con letra inicial mayúscula } \\
(3.3 .3 . j, \text { nota } 28)\end{array}$ \\
\hline $\begin{array}{l}\text { Suelen escribirse con mayúscula } \\
(3.3 .4)\end{array}$ \\
\hline
\end{tabular}

\section{Ortografia/74}

No es preceptivo, pero responde a uso personal frecuente, iniciar con mayúscula $\left(\$ 6.9 .^{\circ}\right)$

Suele emplearse mayúscula a principio de cada verso $\left(\$ 6.12 .^{\circ}\right)$

No es preceptivo, pero responde a uso personal frecuente, iniciar con mayúscula $\left(\$ 6.9^{\circ}\right)$

En muchos de estos casos la mayúscula orienta al lector respecto al significado que ha de dar a la palabra $\left(\$ 6.9^{\circ}\right)$

También se escriben con mayúscula

No es preceptivo. $\left(\S 6.9^{\circ}\right)$

(3.3.4.a-c)

En ocasiones, el uso de mayúsculas se debe a propósitos expresivos (3.5.a)

Se escribirán con mayúscula inicial [...] cuando equivalgan a nombres propios $\left(\$ 6.3 .^{\circ}\right)$

Sin embargo, pueden escribirse con mayúscula (3.5.a)

[...] se escribirán con mayúscula $[. .$.$] cuantas veces$ fueren nombrados en esta forma $\left(\$ 6.3^{\circ}\right)$

También es costumbre particular [...] Suelen escribirse con mayúscula $\left(\$ 6.8^{\circ}\right)$ escribir con mayúscula (3.5.a)

En ningún caso deben extenderse estos empleos (3.5.b)

USO DE LAS LETRAS MINÚSCULAS

Fórmulas de prescripción y descripción de uso

\begin{tabular}{|l|l|}
\hline \multicolumn{1}{|c|}{ Ortografía/99 } & Ortografia/74 \\
\hline $\begin{array}{l}\text { Se escribirán con minúscula (3.2.2, } \\
\text { nota 25) }\end{array}$ & \\
\hline Se escribirá con minúscula $(3.3 .2 . d-f)$ & \\
\hline $\begin{array}{l}\text { Se escribirá también con minúscula } \\
(3.3 .2 . d)\end{array}$ & \\
\hline Deberá escribirse $(3.3 .2 . l)$ & \\
\hline No debe llevar mayúscula $(3.3 .3 . d)$ & No debe llevar mayúscula $\left(\$ 6.4 .^{\circ}\right)$ \\
\hline
\end{tabular}




\begin{tabular}{|l|l|}
\hline \multicolumn{2}{|c|}{ Fórmulas de prescripción y descripción de uso } \\
\hline \multicolumn{1}{|c|}{ Ortografia/99 } & \multicolumn{1}{|c|}{ Ortografia/74 } \\
\hline $\begin{array}{l}\text { Pero se utilizará la minúscula inicial } \\
(3.3 .3 . f)\end{array}$ & \\
\hline $\begin{array}{l}\text { Pero escribiremos con minúscula } \\
(3.3 .3 . h)\end{array}$ & \\
\hline Se escribirán con minúscula $(3.3 .3 . j)$ & $\begin{array}{l}\text { Cuando no encabecen párrafo o escrito, o no for- } \\
\text { men parte de un título, se recomienda escribir con } \\
\text { minúscula }\left(\S 6.100^{\circ}\right)\end{array}$ \\
\hline $\begin{array}{l}\text { Se recomienda, en cambio, escribir con } \\
\text { minúscula (3.4) }\end{array}$ & \\
\hline $\begin{array}{l}\text { Se escribirán siempre con minúscula } \\
\text { (3.5.a) }\end{array}$ & \\
\hline
\end{tabular}

\section{Análisis de las fórmulas. Reformulaciones y variaciones estilísticas. Letras mayúsculas}

A) En ORAE/99 se encuentra la fórmula "se escribirán con letra inicial mayúscula" -que afecta a 30 casos (4, correspondientes a "3.3.1. En función de la puntuación"; 15, "3.3.2. En función de la condición o categoría"; 11, "3.3.3. En función de otras circunstancias") redactada con el futuro de valor modal obligativo, con el futuro de mandato ${ }^{10}$. Este futuro yusivo marca la norma de los casos de una sola variante: nombres propios (esenciales o accidentales) y palabra con mayúscula inicial porque, o empieza escrito, o lo exige la puntuación. De esta fórmula depende la subfórmulas "comenzarán por mayúscula" (3.3.2.b), "se escribirán con mayúscula solo cuando encabecen" (3.3.2.c), "se escribirán también con mayúscula" (3.3.2.c), "se escribe con mayúscula" (3.3.2.b).

B-1) La fórmula "En ocasiones se emplean letras mayúsculas [...]. Suele hacerse así:", que afecta a 5 casos (3.2.1-5), la utilizan los redactores para señalar usos consuetudinarios en sectores profesionales de la edición e impresión de libros, periódicos, revistas, etc. y en las prácticas de la muchas burocracias (3.2.5). Pero también se comprueba, fuera y dentro de esos sectores, un empleo frecuente en minúscula por la lógica de la norma general (no escribir con letras mayúsculas palabras o frases enteras). Se trata de las descripciones de uso $3.2,3.2 .1,3.2 .2,3.2 .3,3.2 .4,3.2 .5$ y 3.3.4. De las cuales, 3.2 .2 (uso de mayúsculas en siglas y acrónimos), 3.2 .3 (uso de mayúsculas en cabeceras de diarios y revistas) y 3.2 .5 (uso de mayúsculas en documentos jurídicos y administrativos) son nuevas en ORAE/99. La fórmula "Suelen escribirse con mayúscula..." (en 3.3.4, un caso) la emplean para señalar el uso de la mayúscula inicial en los actos burocráticos para los nombres de determinadas 
entidades consideradas conceptos absolutos: la Justicia, por ejemplo; norma desglosada del uso 6.9. ${ }^{\circ}$ de ORAE/74 ("No es preceptivo, pero responde a uso personal"). La norma 3.2.1 es un caso similar al anterior, pero referida al ámbito y uso tipográfico profesional y de la edición. Se comprueba, pues, que la fórmula con perífrasis verbal con valor reiterativo de este grupo de normas suelen emplearla los redactores en los casos de opción posible, por no quedar sujetos esos casos a las normas generales de "nombres propios" -de cualquiera especie- y de "posición" que no admiten variación alguna (3.3).

B-2) La subfórmula "Se escribe con mayúscula.." (3.3.2.b) depende de un epígrafe superior con fórmula de norma de tipo $A$, "Se escribirá...", y es parte de una cadena de condicionantes y condicionados con un esquema "Cuando...FORME..., ...COMENZARÁN por mayúscula...". || "Se ESCRIBE con mayúscula..., cuando FORMA parte...". El uso de este presente puede deberse, bien a la concordancia temporal impuesta y debida a la intención de variar estilísticamente para evitar la repetición monótona de las mismas fórmulas de prescripción, bien a que los redactores utilizan el presente no marcado descriptivo por tratarse de nombres comunes que forman parte de nombres propios pluriverbales, los cuales exigen, para conocimiento de su condición de tales, de conocimientos culturales extralingüísticos complementarios de las normas ortográficas, pero que no se pueden deducir de ellas ${ }^{11}$. También puede deberse a otro tipo de variación que, hoy por hoy, se me oculta.

B-3) Las fórmulas "En ocasiones, el uso de mayúsculas se debe a propósitos expresivos..." (3.5), "Sin embargo, pueden escribirse con mayúscula..." (3.5.a) ๆ 3) y "También es costumbre particular [...] escribir con mayúscula" (3.5.a 6) sirven a los redactores académicos para, bajo el epígrafe "Empleos expresivos" (3.5), "desmenuzar" la norma de la ORAE/74 que simplemente razonaba: "Se escribirán con letra inicial mayúscula [...] títulos y nombres de dignidad [...], nombres y apodos [...] y particularmente los dictados generales de jerarquía o cargo importante cuando equivalgan a nombres propios [...]; pero se deberá usar de minúscula, por ejemplo, en vulgar sentencia $[\ldots]$ ". ( $\$ 6$ y 6. 3. ${ }^{\circ}$ ). Estamos ante nombres comunes elevados a propios, o por motivos sociales protocolarios, o por costumbre particular, o por estar en lugar del nombre propio. Como nombres comunes que son, se escriben con minúscula fuera de esos casos; en consecuencia, los redactores no emplean el futuro de mandato, sino el presente descriptivo de usos y costumbres sectoriales.

C) La fórmula contundente "En ningún caso deben extenderse estos empleos..." (3.5.b I 2) la utilizan los redactores académicos para alertar contra el uso expresivo de mayúsculas por minúsculas (y viceversa) en textos que no sean publicitarios, propagandísticos o similares. En esta fórmula, "El verbo deber en su acepción propia de «hallarse obligado», «tener obligación» no es auxiliar; deber + INFINITIvo no es, por consiguiente, una frase verbal [...]"12; sino que se trata de una orden clara y expresa.

D) En la fórmula "se escribía con letra inicial mayúscula..." (3.3.3.j, nota 28), que ha sustituido a la norma $\$ 6.12 .^{\circ}$ de ORAE/74 ("Suele emplearse mayúscula a principio de cada verso [...]. En la poesía moderna es frecuente encabezar los versos con minúscula"), el pretérito imperfecto descriptivo de hábitos y de costumbres lo emplean los redactores

11 Eugenio Coseriu en Teoría del lenguaje y lingïistica general, Editorial Gredos, Madrid, 1967, pág. 265, nota 12, afirma: "En efecto, la «lengua» es un saber, una técnica [...], pero es un saber acerca de modelos y esquemas lingüísticos, y no acerca de los objetos. Acerca de los objetos informan la experiencia y las ciencias no-lingüísticas". 
para anotar la historia de los gustos ortotipográficos de los poetas de otros tiempos. Podían haber añadido, para conocimiento del "gran público al que va dirigida" la Ortografía, que la poesía moderna y actual, casi sin excepciones, prefiere el uso de minúscula.

\section{Fórmulas de prescripción, descripción y uso de las letras minúsculas}

E) Las fórmulas "Se escribirán con minúscula, en cambio, los que con el uso se han convertido en nombres comunes" (3.2.2. nota 25), "Se escribirá con minúscula" (3.3.2.d-f), (3.3.3.j), "En los títulos, cargos y nombres de dignidad, como Rey, Papa, Duque, Presidente, Ministro etc. [ๆ] Estas palabras se escribirán siempre con minúscula cuando acompañen al nombre propio [...] o estén usados [usadas] en sentido genérico" (3.5) y "Se utilizará la minúscula..." (3.3.2.b 3), con el futuro de valor modal obligativo, las emplean los redactores de la ORAE/99 para indicar que se trata de palabras con condición de nombres comunes o adjetivos en los que solo cabe la posibilidad de escribirlos con minúscula.

F) Fórmula única en futuro imperfecto de indicativo, primera persona del plural: "Pero escribiremos con minúscula: Me gustan las matemáticas de este curso" (3.3.3.hף2), fórmula al estilo de libros de texto escolares de las últimas décadas, que, en este caso, tal vez, la utilicen los redactores para, aproximarse al lector ${ }^{13}$, para implicarlo y compartir con él la obligación de la norma, o tal vez, se deba a mera variación estilística.

G) La subfórmula "deberá escribirse con minúscula..." (3.3.2.l) la emplean, como en el caso $C$, los redactores para dar una orden contraria dentro de la fórmula general "se escribirá con letra inicial mayúscula" del apartado (3.3.2). En el mismo caso estamos en "Cuando se escribe con todas las letras, usted no debe llevar mayúscula" (3.3.3.d) que depende de igual fórmula general. Esta es la norma consensuada que hay que respetar y acatar. Pero ese Usted con mayúscula bien puede entrar dentro del apartado de empleos expresivos (3.5), sujetos a "costumbre particular" de respeto y veneración de personas dignas de ello.

H) Esta fórmula, "Se recomienda, en cambio, escribir con minúscula inicial los nombres de los días de la semana, de los meses y de las estaciones del año", esta recomendación, en apartado especial solo para ella (el 3.4, Minúscula inicial), ya figuraba el ORAE/74, pero redactada de forma más clara para el lector, pues, quien vaya a leer directamente el apartado 3.4 no tiene por qué leer antes el desarrollo de 3.3, que es un epígrafe anterior del mismo nivel e independiente, por lo tanto, del posterior; sin embargo, el "en cambio" de la fórmula obliga a leer el epígrafe anterior para comprender que, como a 3.3, al epígrafe 3.4, le afecta también lo que recoge ORAE/74 en el párrafo $\S 6.100^{\circ}$ ("Cuando no encabecen párrafo o escrito o no formen parte de un título [...] los días de la semana, meses [...]”). A pesar de la recomendación de la minúscula, que no orden, la grafía con mayúscula podrá deberse, unas veces, a que el que escribe siente cada lunes, cada enero y cada invierno como únicos: no se repiten...: son otros: pasan y no vuelven; y, por lo tanto, tiende a hacerlos irrepetibles, como los seres humanos, que cada uno tiene su nombre propio válido solo para él; otras veces, el motivo para emplear mayúscula tal vez provenga de la imagen presente en lugar visible de los tradicionales almanaques de pared y de los calendarios de sobremesa y agendas que

13 ORAE/74 lo utiliza en $\S 6.14 .^{\circ}$. ORAE/99, emplea también la primera persona del plural del presente de indicativo en los casos 3.3.2.f y 3.5.a. 
usan de solas mayúsculas para los nombres de días y meses; $y$, otras veces, el motivo para usar la mayúscula pudiera fundarse en el especial interés de aquel que escribe en que se fije el que lee en la fecha de una cita de cualquier tipo, etc., y, para lograrlo, levanta hitos para que el ojo apunte a la mayúscula y no olvide.

I) La fórmula "Algunos impresores utilizan letras minúsculas en este último caso: página xxii, xvi, etc." (3.2.4, nota 27) tal vez sobre, ya que se limita a constatar el uso de "algunos impresores", que, según mi manejo y consulta de libros, imitan este uso anglosajón por tratarse, en unos casos, de empresas multinacionales que imponen su globalismo ideológico también en materia tipográfica, $y$, en otros casos, se trata de particulares que, para ser diferentes, imitan lo extraño porque los usos propios de nuestra lengua los ignoran, los desprecian o los suponen inferiores a los que imitan.

\section{Fórmulas de prescripción, descripción y uso de las letras mayúsculas y minúsculas de la ORAE/74 reformuladas en ORAE/99}

A) Cambio de estilo. La fórmula de la ORAE/74 "Cuando hubiere de escribirse con mayúscula [...] sólo se formarán de carácter mayúsculo..." (\$6.14. $\left.{ }^{\circ}\right)$ se ha simplificado con la fórmula de la ORAE/99 "En las palabras que empiezan con un dígrafo, como es el caso de $l l$, ch [...], solo se escribirá con mayúscula la letra inicial" (3.1.2). La fórmula "[...] lo más común es usar de solas mayúsculas, todas, $[\ldots]$ pueden escribirse $[\ldots]$ con todas sus letras mayúsculas" ( $\$ 5 a)$ queda en ORAE/99, como "En ocasiones se emplean letras mayúsculas para destacar palabras o frases enteras de un escrito. Suele hacerse así: [...]" (3.2). Se ha quitado el futuro de subjuntivo ("cuando hubiere") y esa especie de plural expresivo con adjetivo antepuesto -cuasi poético- obligado ("usar de solas mayúsculas, todas") para evitar la cacofonía de la construcción mayúsculas solas, todas.

B) Cambio de fórmula. En ORAE/74, figura la fórmula "Es potestativo escribir con mayúscula o minúscula los sustantivos y adjetivos que entren en el título de cualquier obra: [...]. Claro es que los nombres propios deben escribirse con mayúscula: [...]" ( $\left.\$ 6.7 .^{\circ}\right)$ que la ORAE/99 reformula con la prescripción de "Se escribirán con letra inicial mayúscula: [...] g) [1] La primera palabra del título de cualquier obra. [...]. [2] En las publicaciones periódicas y colecciones, en cambio se escriben con mayúscula los sustantivos y adjetivos que forman el título [...]" (3.3.3. En función de otras circunstancias). Recoge, de esta forma, la nueva edición académica el uso de los editores de revistas. En ORAE/74 aparece "No es preceptivo, pero responde a uso personal frecuente $[\ldots]^{\prime \prime}\left(\S 6.9 .^{\circ}\right)$, fórmula que cambia, en el caso de "los nombres de las disciplinas científicas", para sancionar el uso, hecho norma durante los veinticinco años transcurridos entre las ediciones, con esta nueva fórmula de prescripción: "Se escribirán con letra inicial mayúscula: $[\ldots]$ h) Los nombres de las disciplinas científicas [...]" (3.3.3.h). En el caso de los "[...] seres o conceptos que quien escribe desea destacar por veneración, respeto o énfasis" (6.9. $)$, la fórmula "No es preceptivo [...]" se convierte en "Suelen escribirse con mayúscula los nombres de determinadas entidades [...]. También se escriben [...]" (3.3.4); fórmula, que, a diferencia de las anteriores que prescriben, describe ese uso de relieve gráfico reverencial, que, debido a tal formulación, puede conseguir que tengamos un idioma de mayúsculas solas, ya que esos seres, conceptos, entidades, fechas, acontecimientos, etc. pueden llegar a ser tantos cuantos así decidan todos los que escriben en nuestra lengua. 


\section{Normas nuevas para la "nueva versión" de la Ortografia}

Las 38 normas nuevas que aparecen en ORAE/99 abarcan desde la puntual 3.1.3, que manda que "la $i$ y la $j$ mayúsculas se escribirán sin punto" 14 , hasta las omnipresentes "[...] siglas y acrónimos" (3.3.2), que se escribirán con mayúscula, excepto en su uso como nombres comunes que "se escribirán con minúscula". Y sigue la nueva versión sancionando el gusto de los distintos sectores de la sociedad por las mayúsculas: la prensa (3.2.3) las usa en las cabeceras de sus periódicos y revistas; las muchas administraciones (3.2.5), en su burocracia de papel; las empresas (3.3.2.l), para sus nombres propios; los seres y lugares singulares del universo material e imaginario (3.3.2.d-f), (3.3.3.j), para individualizarse; la religión (3.3.2.g-k), (3.3.3.c-d) y (3.3.4.c), para lo suyo; los que escriben (3.3.3.h) y $(3.5 . b)$, para sus profesiones y actividades; en los textos mismos (3.3.1.b-d) se emplean, en función de la puntuación, para evitar la anarquía puntuaria y tipográfica sin sentido.

Tendencia, pues, a las mayúsculas de ornato, a las mayúsculas que establecen jerarquías, a las mayúsculas que individualizan sin criterio ni sistema. Tendencia que ya fue advertida por José Polo en 1974, en Ortografía y ciencia del lenguaje ${ }^{15}$, y en 1990 , en Manifiesto ortográfico de la lengua española ${ }^{16}$. Para otro artículo y revista que lo acoja, queda demostrar cuánto debe la ortografía académica nueva a autores, ya citados, como Ángel Rosenblat ${ }^{17}$ y José Polo ${ }^{18}$; y a Manuel Seco ${ }^{19}$, José Martínez

14 En la escritura manual (exámenes, por ejemplo) es frecuente ver con punto la $I$ mayúscula, pero no la $J$.

15 Editorial Paraninfo, Madrid, 1974.

16 Visor Libros, Madrid, 1990.

17 También se ocupa de temas ortográficos en "Las ideas ortográficas de Bello" en Andrés Bello, Obras completas, Ministerio de Educación, Caracas, 1951, v, págs. Ix-cxxxvill, y en Sentido mágico de la palabra, Ediciones de la Biblioteca, Caracas, 1977.

18 Otros trabajos de José Polo sobre ortografía (o en los que, entre otros aspectos, se trata de ella): “A propósito del Diccionario de dudas de Manuel Seco", en Revista de Filologia Española, Lı, págs. 243-265; "Hacia una política cultural de la lengua española", en Arbor, 450, 1983, págs. 61-67; "Textos de lingüística y visión normativa. A propósito de la última edición en español, 1983, del Curso de Saussure", en Anuario de Estudios Filológicos [Universidad de Cáceres], xIII, 1990, págs. 311-330; "Nota sobre cuestiones editoriales y ortotipográficas. Los malos ejemplos", en Revista de Filología, Universidad de la Laguna, 10, 1991, págs. 389-394; "Dos momentos ortográficos en nuestro IV Simposio (coordinados por José Polo)" en Benjamín Mantecón Ramirez y Francisca Zaragoza Canales (eds.), La gramática y su didáctica (Actas del IV Simposio Internacional de la Sociedad Española de Didáctica de la Lengua y la Literatura), Universidad de Málaga, 1996, pp. 135150; "Introducción al comentario ortográfico" en Manuel Crespillo (ed.) y Pilar Carrasco (comp.), Comentario lingüístico de textos, Anejo de viı de Analecta Malacitana, Málaga, 1997, págs. 123-162; "Sobre la correspondencia Cuervo-Menéndez Pidal (1) y (2)", en RFE, LXXXI, 2001, págs. 165-183 y 273-316, respectivamente; Criterios tradicionales y renovadores en la ortografia. Transcripción de una histórica mesa redonda [organizada y moderada por J. Polo] (SEL, diciembre de 1984), Sociedad Española de Lingüistica, Madrid, 2001; "La ortografía y su enseñanza (notas de un coloquio)" en Juan A. Moya (ed.), La enseñanza de la lengua española en los textos. Actas de las quintas jornadas sobre la enseñanza de la lengua española, Universidad de Granada, 2000, págs. 213-218; "Problemas ortográficos en la enseñanza de la lengua española" en Jerónimo de las Heras Borrero y otros (eds.), Modalidad lingüistica andaluza. Medios de comunicación y aula, Edita J. P. Carrasco, Huelva, 2002, págs. 259-309.

19 Manuel Seco, "Apéndice de fonética y ortografía" en Rafael Seco, Manual de gramática española, Madrid, ${ }^{3} 1958$; en la ${ }^{4} 1960$, añade un capítulo en el que "expone metódicamente las Nuevas normas de prosodia y ortografia establecidas de manera preceptiva por la Real Academia desde 1959". Manejo la edición de ${ }^{10} 1975$ de la editorial Aguilar, págs. 259-330; Metodología de la Lengua y Literatura Españolas en el Bachillerato, Ministerio de Educación y Ciencia, Publicaciones de la Dirección General de Enseñanza Media, Madrid 1961 y ${ }^{2} 1966$, págs. 47-49, 78-81; Gramática esencial del español. Introducción al estudio de la lengua, Editorial Aguilar, Madrid, 1972, págs. 3767 de los caps. 4 y 5, dedicados a los sonidos y la ortografia; "Repensar la ortografia" en Arbor, 350/1975, págs. 97-106 (artículo reseña sugerido por la lectura de la obra de J. Polo, 1974, citada). 
de Sousa ${ }^{20}$, Hilda Basulto ${ }^{21}$, Lidia Contreras ${ }^{22}$, Jesús Mosterín ${ }^{23}$, Francisco Marcos Marín ${ }^{24}$, etc., que, constructivamente, han escrito para mejorar la ortografía académica; pero no publican, para provecho propio, "ortografías comerciales" que la parafrasean y engordan embrollándola (empleado este verbo en todas las acepciones del último Diccionario académico).

20 José Martínez de Sousa, Diccionario de tipografia y del libro, Editorial Labor, Barcelona, 1974 y Paraninfo, Madrid, ${ }^{3} 1992$; Diccionario de ortografia técnica, Ediciones Pirámide, Madrid, 1987; Reforma de la ortografia española, Visor Libros, Madrid, 1991; Manual de estilo de la lengua española, Editorial Trea, Gijón, 2000, 22001; Diccionario de edición, tipografia y artes gráficas, Editorial Trea, Gijón, 2001; Libro de estilo de Vocento (partes 2, 3 y 4), Editorial Trea, Gijón, 2003.

21 Hilda Basulto, Ortografia actualizada, Editorial McGraw-Hill, México, D. F., 1986.

22 Lidia Contreras F., Historia de las ideas ortográficas en Chile, Editorial Universitaria, Santiago de Chile, 1993; Ortografia y grafémica, Visor Libros, Madrid, 1994.

23 Jesús Mosterín, La ortografia grafémica del español, Alianza Editorial, Madrid, 1981.

24 Francisco Marcos Marín, "La ortografia: entre el estupor y la norma" en Revista de Bachillerato, Cuaderno monográfico, 9, 1982, págs. 23-27 (recogido en su libro Comentario de lengua española, Alhambra, Madrid, 1983, págs. 9-19). 